taught to put the shoulder through its complete range of movement several times a day and to use the Australian technique when lifting the patient. ${ }^{4} 51011 \mathrm{~A}$ sling was first suggested in $1952^{12}$ to prevent subluxation and frozen shoulder, and there has been considerable disagreement concerning its use. The main disadvantages are that it interferes with body image, the postural support of the arm, good gait training, and reciprocal arm swinging. ${ }^{213}$ Correct handling of the patient in the early stages of a stroke is crucial in preventing the consequences of malalignment of the shoulder.

We thank the doctors, nurses, and rehabilitation staff of the Royal Victoria Hospital, Edinburgh, for their co-operation; Mrs O Brodie for taking the radiographs; Professor J Williamson for his helpful criticism; and Mrs A Burt and Miss K Hamilton for their secretarial help.

\author{
References \\ 1 Taketomi Y. Observations on subluxation of the shoulder joint in hemi- \\ plegia. Phys Ther 1975;55:39-40.
}

${ }^{2}$ Miglietta O, Lewitan A, Rogoff JB. Subluxation of the shoulder in hemiplegic patients. NY State 7 Med 1959;59:457-60.

${ }^{3}$ Najenson T, Pikielny SS. Malalignment of the gleno-humeral joint following hemiplegia. Ann Phys Med 1965;8:96-9.

4 Fitzgerald-Finch OP, Gibson IIJM. Subluxation of the shoulder in hemiplegia. Age Ageing 1975;4:16-8.

5 Tobis JS. Problems in rehabilitation of the hemiplegic patient. NY State f Med 1957;57:1377-80.

${ }^{6}$ Moskowitz H, Goodman CR, Smith E, Balthazar E, Mellins HZ. Hemiplegic shoulder. NY State $\mathcal{F}$ Med 1969;69:548-50.

${ }^{7}$ Garraway WM, Akhtar AJ, Prescott RJ, Hockey L. Management of acute stroke in the elderly: preliminary results of a controlled trial. Br Med F 1980;280:1040-3.

${ }^{8}$ Bierman W, Licht S, eds. Physical medicine in general practice. New York: Hoeber, 1952:601.

${ }^{9}$ Moskowitz E, Bishop HF, Shibutani K. Posthemiplegic reflex sympathetic dystrophy. F $A M A$ 1958;167:836-8.

10 Anonymous. Shoulder pain from subluxation in the hemiplegic. $\mathrm{Br} \mathrm{Med} \mathrm{F}$ 1975; ii:581-2.

${ }^{11}$ Irvine RE, Strouthidis TM. Stiff shoulder after a stroke. Br Med $\mathcal{f} 1978$; $\mathrm{i}: 1622$.

${ }^{12}$ Moskowitz E. Upper extremity complications in hemiplegic patients. Manitoba Med Rev 1967;47:448-50.

${ }^{13}$ Anonymous. Painful shoulders and painful arcs. Br Med F 1977;ii:913-4.

(Accepted 9 March 1982)

\title{
Objective test for food sensitivity in asthmatic children: increased bronchial reactivity after cola drinks
}

\author{
N WILSON， H VICKERS，G TAYLOR，M SILVERMAN
}

\begin{abstract}
Ten asthmatic children with a history of cough and wheeze after drinking a cola drink performed histamine inhalation tests before and 30 minutes after a drink of Pepsi-Cola, soda water, and water on three separate study days. There was no significant change in baseline peak expiratory flow after any of the three drinks. Sensitivity to histamine was increased after the cola drink ( $p<0.005)$ but was not significantly different after soda water or water.

The detection of change in sensitivity to histamine appears to be a simple and effective method of testing for food sensitivity in asthma.
\end{abstract}

\section{Introduction}

The overall importance of food sensitivity in childhood asthma is unknown. Several substances such as nuts, eggs, milk, chocolate, and fish ${ }^{1}$ as well as food additives such as sulphur dioxide, benzoate, and tartrazine ${ }^{2}$ cause wheezing in asthmatic subjects. When the reaction is severe and immediate, diagnosis is not a problem. Sometimes, however, the symptoms are mild, intermittent, or delayed, and a proportion of subjects with a history of such wheezing do not respond to an oral challenge test. $^{12}$ In a pilot study we found that five asthmatic children

\footnotetext{
Department of Paediatrics and Neonatal Medicine, Hammersmith Hospital, London W12 0HS

$\mathrm{N}$ WILSON, $\mathrm{MB}, \mathrm{DCH}$, research fellow

$\mathrm{H}$ VICKERS, BSC, research assistant

G TAYLOR, MB, MRCP, research fellow

M SILVERMAN, MD, MRCP, senior lecturer
}

giving a definite history of symptoms of cough and wheeze after a cola drink failed to show any change in their peak expiratory flow measured before and serially for two hours after an oral challenge. We suspected that rather than inducing airways obstruction directly the cola had its clinical effect by enhancing airways reactivity, so that common environmental provoking factors such as exercise could more readily precipitate an attack of asthma.

We designed the present study to compare airway sensitivity to inhaled histamine before and after an oral challenge to see whether a change in the degree of airway hyperreactivity might account for the alleged symptoms of cough and wheeze. Cola was chosen as the test substance as we had already shown no gross change in resting peak expiratory flow after such a drink and it was easy to eliminate from the diet preceding the test.

\section{Methods}

Ten asthmatic children giving a history of cough and wheeze after a drink of cola were selected (no particular brand was specified). Their mean age was 13.2 years (range $7-17$ ), and nine were male. They attended the laboratory on three separate days but at the same time of day on each occasion. Beta-agonists were stopped for at least eight hours and sustained-release aminophylline for 24 hours before each study period. None of the subjects were taking cromoglycate, inhaled steroids, or an antihistamine preparation. Nine were from the Indian subcontinent.

A standard protocol was used on each of the three study days. After baseline peak expiratory flow had been recorded with a Wright peak flow meter (the maximum value over three attempts was accepted) histamine challenge was performed after the method described by Cockcroft et al. ${ }^{3}$ After inhalation of a control solution of $0.9 \%$ saline for two minutes increasing concentrations of histamine were inhaled for two minutes each, at five-minute intervals, from a Wright nebuliser. Peak expiratory flow was recorded 30, 90, and 120 seconds after the end of each inhalation. The procedure continued using doubling 
concentrations of histamine (from 0.063 to $8 \mathrm{~g} / \mathrm{l}$ ) until at least a $20 \%$ fall in peak expiratory flow from the control value had been recorded. A dose-response curve was constructed and the dose that caused a $20 \%$ fall in peak expiratory flow $\left(\mathrm{PC}_{20}\right)$ calculated by interpolation. Thirty minutes after the first histamine challenge a test drink was given. This was followed by serial measurements of peak expiratory flow for a further 30 minutes, when a second histamine challenge was performed in a manner identical with the first. The test drink on the first two days was $200 \mathrm{ml}$ of either Pepsi-Cola (cola) or soda water containing five drops of saccharin solution (soda) given in random order. It was administered in a double-blind fashion by an independent observer through a straw, from a foil-covered container. The children were told merely that the effects of fizzy drinks were being tested. In fact, many found it impossible to distinguish between the cola and the sweetened soda water. On the third occasion the test drink was tap water containing five drops of saccharin solution (water). On this occasion the investigator was aware of its nature but the subject was told only that it was another drink. All drinks were given at room temperature.

Differences in mean peak expiratory flow and histamine $\mathrm{PC}_{20}$ were assessed by paired $t$ tests. All analysis on $\mathrm{PC}_{20}$ was performed after logarithmic transformation to produce a linear scale.

\section{Results}

Peak expiratory flow-There was no significant difference in baseline peak expiratory flow between the three study days (table I). On

TABLE I-Mean $( \pm S D)$ peak flow rate (l/min) at each stage of study

\begin{tabular}{|c|c|c|c|c|c|c|}
\hline & & & & $\begin{array}{l}\text { Before first } \\
\text { histamine } \\
\text { challenge }\end{array}$ & $\begin{array}{l}\text { Before } \\
\text { test drink }\end{array}$ & $\begin{array}{l}\text { Before second } \\
\text { histamine } \\
\text { challenge }\end{array}$ \\
\hline $\begin{array}{l}\text { Cola } \\
\text { Soda } \\
\text { Water }\end{array}$ & $\because$ & 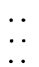 & $\because$ & $\begin{array}{l}333 \pm 143 \\
333 \pm 131 \\
348 \pm 108\end{array}$ & $\begin{array}{l}310 \pm 128 \\
301 \pm 104 \\
320 \pm 100\end{array}$ & $\begin{array}{l}312 \pm 113 \\
310 \pm 119 \\
335 \pm 98\end{array}$ \\
\hline
\end{tabular}

No differences reached statistical significance (paired $t$ test).

each day the mean peak expiratory flow before the first histamine challenge was slightly higher than that before the second, but in no case was the difference significant. The drink of cola had no significant effect on the mean peak expiratory flow, which before the drink was $310( \pm S D$ 128) $1 / \mathrm{min}$ and 30 minutes after was $312( \pm 113) 1 / \mathrm{min}$ (table I). In one subject (case 2), however, a $12 \%$ fall in peak expiratory flow occurred 30 minutes after the drink of cola; she was the only subject who showed more than an $8 \%$ change in peak expiratory flow. Neither of the two other drinks caused a significant change in mean or individual peak expiratory flow.

Histamine $P C_{20}$-The mean $\mathrm{PC}_{20}$ before the drink of cola was 2.03 $\mathrm{g} / \mathrm{l}$ and 30 minutes after had fallen to $1.20 \mathrm{~g} / \mathrm{l}$, indicating a highly significant increase in sensitivity to histamine $(p<0.005$, table II). There was no significant difference in the mean histamine $\mathbf{P C}_{20}$ before

TABLE II-Histamine $P C_{20}(g / l)$ before and 30 minutes after each test drink

\begin{tabular}{|c|c|c|c|c|c|c|}
\hline \multirow{2}{*}{$\begin{array}{l}\text { Case } \\
\text { No }\end{array}$} & \multicolumn{2}{|c|}{ Cola } & \multicolumn{2}{|c|}{ Soda } & \multicolumn{2}{|c|}{ Water } \\
\hline & Before & After & Before & After & Before & After \\
\hline $\begin{array}{r}1 \\
2 \\
3 \\
4 \\
5 \\
6 \\
7 \\
8 \\
9 \\
10\end{array}$ & $\begin{array}{l}1.10 \\
1.50 \\
5.20 \\
2.40 \\
1.05 \\
1.25 \\
1.80 \\
1.80 \\
2.40 \\
1.80\end{array}$ & $\begin{array}{l}0.70^{*} \\
0.28^{*} \\
3.60 \\
1.20^{*} \\
1.60 \\
0.43^{*} \\
0.90^{*} \\
0.56^{*} \\
1.45 \\
1.26\end{array}$ & $\begin{array}{l}1.00 \\
0.30 \\
5.40 \\
2.25 \\
1.25 \\
1.12 \\
1.35 \\
1.18 \\
3.60 \\
1.20\end{array}$ & $\begin{array}{l}0.25 * \\
0.46 \\
8 \cdot 00 \\
2.05 \\
1.50 \\
1.20 \\
1.20 \\
1.50 \\
1.25^{*} \\
1.45\end{array}$ & $\begin{array}{l}1 \cdot 10 \\
2.00 \\
3.80 \\
1.40 \\
1.18 \\
1.17 \\
1.25 \\
1.20 \\
1.45 \\
1.90\end{array}$ & $\begin{array}{l}1 \cdot 10 \\
2 \cdot 40 \\
4 \cdot 00 \\
1.35 \\
1 \cdot 25 \\
1.25 \\
1.20 \\
1.12 \\
1.40 \\
1.70\end{array}$ \\
\hline $\begin{array}{l}\text { Mean } \\
\text { SD }\end{array}$ & $\begin{array}{r}2.03 \\
\pm 1.20\end{array}$ & $\begin{array}{r}1.20 \\
\pm 0.95\end{array}$ & $\begin{array}{r}1.87 \\
\pm 1.52\end{array}$ & $\begin{array}{r}1.89 \\
\pm 2.20\end{array}$ & $\begin{array}{r}1.65 \\
\pm 0.82\end{array}$ & $\begin{array}{r}1.68 \\
\pm 0.91\end{array}$ \\
\hline \multicolumn{3}{|c|}{$\begin{array}{l}\text { Significance of } \\
\text { difference }\end{array}$} & \multicolumn{2}{|c|}{ NS } & \multicolumn{2}{|c|}{ NS } \\
\hline
\end{tabular}
* Significant decrease (using twice the within-patient SD from control values; see
Results). and after soda or water. Taking the three control values of $\mathbf{P C}_{20}$, we calculated the confidence limits for $\mathbf{P C}_{20}$ (twice the within-subject standard deviation) for each subject. When these confidence limits were applied, six subjects showed a significant reduction in $\mathbf{P C}_{20}$ after cola and two after soda but none after water. Initially the study was designed using soda as the control drink, but when a positive response occurred in two subjects all the subjects were later retested using water as the control. The difference in mean $\mathbf{P C}_{20}$ before the water challenge from that before the other challenges merely indicates the time that had elapsed since the previous parts of the study. We found a high degree of within-subject reproducibility of $\mathrm{PC}_{20}$. The $95 \%$ confidence limits for $\mathrm{PC}_{20}$ from tests performed one hour apart, before and after the drink of water, were $+0.05 \log$ units. On this criterion nine children responded to cola and two to soda, although in some cases the increase in airways reactivity was minimal.

\section{Discussion}

Non-specific airway reactivity (as shown by a reduction in histamine $\mathbf{P C}_{20}$ ) increased after challenge with cola but not after challenge with soda or water. Depending on the criteria used to assess the reproducibility of histamine $\mathrm{PC}_{20}$, between six and nine of the 10 children showed a significant increase in sensitivity to histamine after drinking cola. All the children had a clinical history of sensitivity to cola drinks.

Although group mean data are important in a general understanding of disease processes, to form the basis of a useful clinical test, the responses of individual patients must be clearly detectable. Thus the criteria of a significant change in histamine $\mathbf{P C}_{20}$ after oral challenge are important. Work by Cockroft et al ${ }^{4}$ suggested that a twofold change in histamine $\mathbf{P C}_{20}$ might be significant. By this criterion sensitivity was increased in five subjects after cola and in two subjects after soda. More recently ${ }^{5}$ Ruffin et al suggested that by using the within-subject standard deviation of $\mathbf{P C}_{20}$ for each individual greater sensitivity might be achieved. This would entail several control values of $\mathrm{PC}_{20}$ for each subject. Clearly the choice of criteria for a change in $\mathbf{P C}_{20}$ remains a practical problem; so too is the clinical interpretation of marginal increases in bronchial reactivity after food challenge.

Although all the subjects had a history of sensitivity to cola drinks, there was no gross change in pulmonary function 30 minutes after a drink of Pepsi-Cola. By using a more sensitive test of airway function we might have been able to show small changes in airway calibre, undetectable by the peak flow meter. The small reduction in mean baseline peak expiratory flow between the first and second histamine challenges was seen on all three study days and therefore could not account for the overall increase in sensitivity to histamine after the cola drink. This difference in baseline peak expiratory flow probably occurred because subjects had not recovered fully from the first histamine challenge by the time of the second.

As no change in resting peak expiratory flow was demonstrable the symptoms after a drink of cola reported by these subjects must have been caused by the increased airway reactivity enhancing the response to an additional provoking factor. In their histories most of the children had indicated that the symptoms came on immediately after a cola drink but that their duration varied from an hour up to two days. Some had said that the effect was not always present and was experienced only if the cola drink was followed by excitement or exercise, thus in their own words suggesting enhanced airway reactivity. Other subjects gave a history of sensitivity to other fizzy drinks, which might explain the reaction to the soda.

From this study no conclusions can be drawn about the mechanism by which the increase in airway reactivity was produced. As it was detectable 30 minutes after ingestion it was unlikely to have been caused by inhalation of carbon dioxide or changes in airway $\mathrm{pH}$. The drinks were all given at room temperature, so airway cooling could not have been a factor. We have used the generic term cola throughout the study, although the tests were carried out with Pepsi-Cola. This is because the subjects were unable to distinguish between the 
various brands of related drinks in giving the history of sensitivity. Related drinks, sharing the responsible ingredient or ingredients, would probably produce a similar response. We believe that this is the first time that cola drinks have been shown to cause symptoms of asthma.

Whatever the mechanism, the clinical relevance of an increase in airway reactivity is clear. Moreover, this method of testing for food sensitivity in asthma by looking for changes in airway reactivity may have much wider implications. Common ingredients of a normal diet might possibly cause symptoms of asthma insidiously, by increasing airway reactivity. The frequency of ingestion and lack of a direct effect on airway function would make diagnosis difficult. As we have shown that pairs of challenges with histamine performed over short intervals are highly reproducible, looking at changes in sensitivity to histamine is a simple and effective method of testing for food intolerance in asthmatic subjects.
We thank the Asthma Research Council and Napp Laboratories for financial help.

\section{References}

1 Galant P, Bullock J, Frick OL. An immunological approach to the diagnosis of food sensitivity. Clin Allergy 1973;3:363-72.

2 Freedman BJ. Asthma induced by sulphur dioxide, benzoate and tartrazine contained in orange drinks. Clin Allergy 1977;7:407-15.

${ }^{3}$ Cockroft DW, Killian DN, Mellor JJA, Hargreave FE. Bronchial reactivity to inhaled histamine: a method and clinical survey. Clin Allergy 1977 $7: 235-43$

4 Cockroft DW, Ruffin RE, Dolovich J, Hargreave FE. Allergen-induced increase in non-allergic bronchial reactivity. Clin Allergy 1977;7:503-13.

5 Ruffin RE, Alpers JH, Crockett AJ, Hamilton R. Repeated histamine inhalation tests in asthmatic subjects. F Allergy Clin Immunol 1981 ;67: 285-9.

(Accepted 18 March 1982)

\section{SHORT REPORTS}

\section{Reversal of male-pattern baldness, hypertrichosis, and accelerated hair and nail growth in patients receiving benoxaprofen}

Benoxaprofen is a non-steroidal anti-inflammatory drug used to relieve symptoms of rheumatoid arthritis and osteoarthrosis. Reported side effects include photosensitivity, onycholysis, urticarial rashes and pruritus, gastrointestinal ulceration and haemorrhage, ${ }^{1}$ and the Stevens-Johnson syndrome. ${ }^{2}$ We have reported the development of toxic epidermal necrolysis, leucopenia, and thrombocytopenic purpura in a patient after nine days' treatment with benoxaprofen. We report here on five patients who developed hypertrichosis and accelerated hair and nail growth, two of whom showed reversal of male-pattern baldness.

\section{Case reports}

Case 1-A 75-year-old man had hereditary male-pattern baldness since he was 45 . At the age of 32 he had developed ankylosing spondylitis, which subsequently affected his lumbar and cervical spine and sacroiliac joints. Treatment with benoxaprofen $600 \mathrm{mg}$ daily gave symptomatic relief. Within a month of starting treatment he developed photosensitivity and onycholysis, which he overcame by using sunscreens and avoiding the sun. After five months' treatment he noticed growth of hairs over an area of scalp that he previously been devoid of visible hair, and on the dorsum of his fingers, hands, and forearms-areas that previously had never had visible hair. $\mathrm{He}$ also noticed accelerated facial hair growth. The density of new hair growth on the scalp was equal to that on the areas of his scalp that were not subject to balding. Growth of scalp hair continued when he took a reduced dose of $300 \mathrm{mg}$ benoxaprofen daily.

Case 2-A 39-year-old woman had had rheumatoid arthritis for severa years. Benoxaprofen $600 \mathrm{mg}$ daily afforded good symptomatic relief. During the first month of treatment she developed a transient pruritic, erythematous papular eruption on the dorsum of her hands; this cleared within a week. After four months' treatment with benoxaprofen she reported an increased rate of growth of scalp hair. She then developed new hair growth on the dorsum of fingers and toes, areas that had been before hairless to the naked eye. This persisted with benoxaprofen treatment. At no time did she describe photosensitivity or develop onycholysis.

Case 3-A 70-year-old woman with longstanding osteoarthrosis was treated with benoxaprofen $600 \mathrm{mg}$ daily, which afforded an improvement in her symptoms. During the first two weeks' treatment she described photosensitivity on exposure to the sun. After three weeks' treatment she developed a growth of downy blonde hair over her face (figure), limbs, and trunk. The hypertrichosis regressed soon after she stopped taking benoxaprofen.

Case 4-A 70-year-old woman had had osteoarthrosis for about 20 years. Benoxaprofen $600 \mathrm{mg}$ daily afforded good symptomatic relief. During treatment she developed photosensitivity on exposure to the sun. After one month's treatment she noticed a growth of fine blonde hairs on her face and later on her arms and legs. These areas had previously been devoid of visible hair. She continued taking benoxaprofen and the hypertrichosis persisted.
Case 5-A 45-year-old man had had hereditary male-pattern baldness since he was 40 . At the age of 39 he had developed psoriatic arthropathy affecting his hands and wrists. He was treated with benoxaprofen $600 \mathrm{mg}$ daily and gained considerable relief of symptoms. Within one month of starting treatment he had developed photosensitivity, which was successfully controlled by use of sunscreens. Onycholysis developed after two months' treatment. After nine months' treatment he noticed an increased growth of hair over the area of scalp previously lacking hair. He also reported an increased rate of growth of his finger nails. Treatment was reduced to $300 \mathrm{mg}$ daily and the growth of new scalp hair and accelerated nail growth continued.

\section{Comment}

Hypertrichosis and accelerated hair and nail growth have not previously been described with benoxaprofen. All but one of the above patients had photosensitivity, and generally the new hair grew on sites exposed to sun. The hypertrichosis continued even when

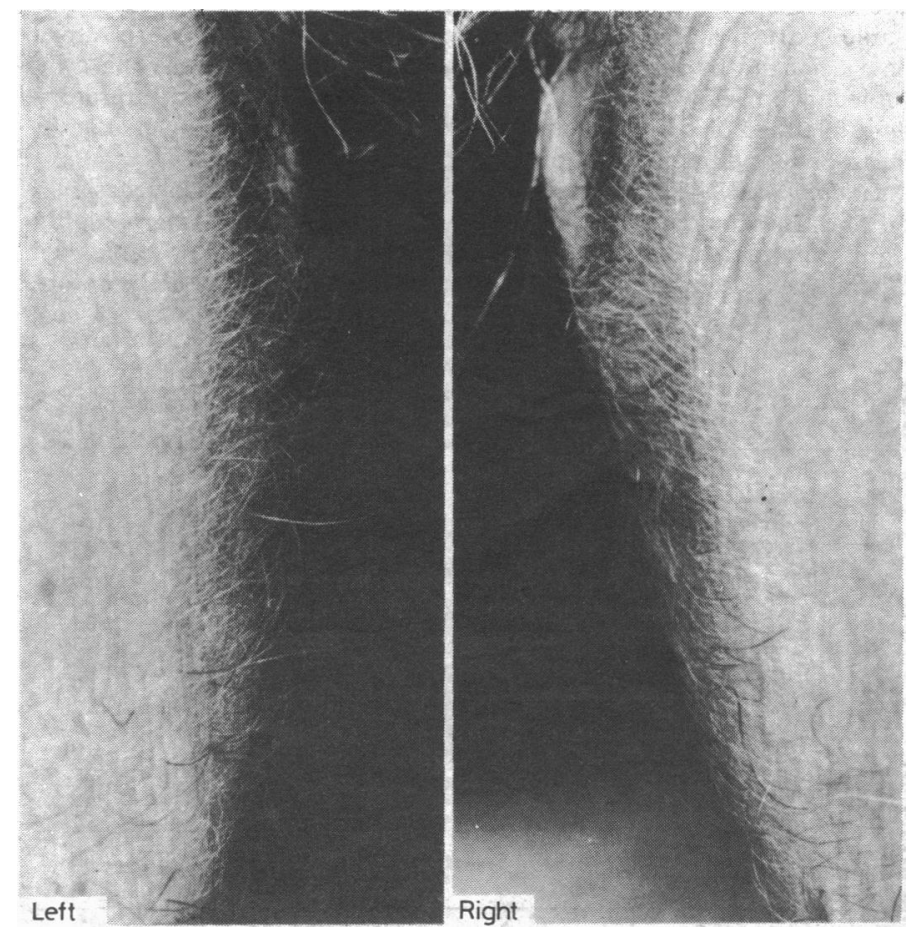

Left and right cheeks of woman with hypertrichosis after benoxaprofen. 